\title{
Design and construction of embankments on an alluvial plain
}

\author{
N. J. DALLARD
}

\section{Mr R. Murray, Road Research Laboratory}

The site selected for the Avonmouth Interchange was in an area where very adverse subsoil conditions existed. Constructing the interchange mainly of earthworks required approach embankments up to $9 \mathrm{~m}$ high and settlement predictions based on data from laboratory consolidation tests indicated that over $600 \mathrm{~mm}$ of settlement would occur, most of this movement taking place after the road was opened to the traffic. In addition, stability calculations suggested that the factor of safety against shear failure might be low. However, recent research has shown that frequently settlement proceeds at a much faster rate than is predicted from theory using the results from conventional laboratory tests. It was considered worthwhile, therefore, to construct a trial embankment which could ultimately be incorporated in the main embankment on the site of the interchange.

43. The aim of this work was to establish whether embankments of the heights required at the interchange could be built without shear failure and whether settlement of the embankments subsequent to the completion of construction would result in unacceptable deformation of the road surface.

44. The measurements from the trial have shown that although the ultimate predicted and field settlements are likely to be in close agreement, the use of the conventional theory of consolidation together with the data from laboratory consolidation tests produced very significant underestimates of the rate of movement, and settlement in the field occurred about 30 times more rapidly than was predicted. Design of the road structure on this basis would therefore have led to expensive foundation techniques being employed which were unnecessary.

45. To provide a better assessment of the soil parameters which govern the consolidation process, measurements were made of the in situ permeability. A more satisfactory settlement prediction was obtained using these results. Details of this work are given in a recent Road Research Laboratory Report. ${ }^{8}$

46. Further research is being carried out by the Laboratory to assess the validity of this method at other sites. The aim of the work is to provide a rational approach to the design of embankments founded on compressible alluvium without the need to construct trial embankments. Such embankments require to be designed and constructed well in advance of the main contract if full use is to be made of the information obtained, and in addition the instrumentation, construction and observations may involve considerable expenditure.

\section{Dr A. B. Hawkins, Bristol University}

My own research is associated with the Late Quaternary geology of the Severn Estuary region. I was therefore slightly disappointed in the rather brief comments on the geology in the Paper. I should like to refer to four topics that could be of interest to engineers who are constructing embankments on recent alluvial deposits. They are: (a) buried valleys; $(b)$ sea level changes and their effects on sediment consolidation; (c) texture of the sediment; $(d)$ pills or creeks across the alluvial levels.

48. The M5 Motorway near Avonmouth runs almost parallel to the side of an ancient buried valley system of the River Severn. If the motorway had been moved

Paper published Proc. Instn Civ. Engrs, 1971, 49 (June) 157-170. 
slightly to the east, parts of it could have been across a very steep valley side. If it had been moved slightly to the west, it would have been across much thicker alluvium.

49. The alluvial sediments of the area are of a very young geological age. An in situ tree stump at $\mathbf{- 1 8} \mathrm{ft} \mathrm{OD}$, approximately the height of the base of the alluvium under the M5, has been dated at 7030 years B.P. Consequently, we can assume that the sediment under the particular trial embankment has formed within the last 7000 years,

50. I would like to stress the potential danger in showing sections between boreholes by the use of solid lines, as in Fig. 2. This assumes a consistency which is rarely true and consequently can be misleading.

51. The laminated nature of intertidal deposits and effect of this on the dissipation of pore water is known to engineers. However, whilst many of the sediments were originally accreted as laminated deposits, they have often suffered bioturbation and consequently, lost their laminations. This bioturbation may be localized or widespread. It is often more ubiquitous in the slower intertidally deposited upper sediments, but may occur at all depths. The inconsistency of the laminations will be important in the differential rates of pore-water dissipation. The localized nature of laminations can be seen in parts of the estuary at present at about mean to low tide level. At one locality, rills have developed through the laminated sediments, about $1 \mathrm{~m}$ apart. These are then infilled with either tilted, broken-off laminated deposits or unlaminated silty clay. A borehole through such sediments would not indicate their true nature.

52. Pills which cross the accumulating sediments are also of importance to the engineer and may help to explain some irregularities he may find in his geotechnical observations. At present, there is often little indication of these pills inland of the sea walls, but their original magnitude, when they drained the floodwaters (both tidal and freshwater) from the accreting sediments, is well-known to geologists.

53. In accreting mudflat sediments the accretion of the pills is usually on the convex bank, often with initial bedding up to $20^{\circ}$. An example of this type of tidal pill sediment has been obtained from the Somerset section of the M5. Here the laminations are dipping and hence the bearing capacity of the sediment and its potential pore-water dissipation rate may be different from the surrounding sediments with horizontal laminations. Both on mudflats and on salt marshes, the tidal pills will be in areas of different sedimentary type, and frequently have minor slips; consequently, the laminations will often be haphazard. Further, there will probably be the accumulation of peaty deposits in the late stage of salt marsh accretion. All these facts occur within areas of horizontal, well-laminated deposits. They may also be almost completely obliterated and only seen under special circumstances.

54. The importance of the tidal pills to engineering geology is currently being investigated and will be reported in the near future.

\section{Mr D. Cook, Bath University}

In the course of construction, settlement records were maintained at no fewer than 26 points along the line of the motorway. In the context of these records I should like to draw attention to two soil mechanics aspects of this material, namely, the time rate of settlement and its degree of preconsolidation.

56. First, however, I should like briefly to review the classification of the material. The properties shown in Fig. 10 relate to about a dozen borings put down to the west of the motorway line. The general succession was substantially the same as the motorway. For reasons which Dr Hawkins described, there is seldom any constant degree of repetition or consistency in the detailed succession between borings, even when they lie quite close. However, the lower chart in the figure, which plots the Atterberg limits against clay friction, does suggest that the clay friction is predominantly illite. Otherwise, liquid limit values are measurable in successive laminations, which vary from as high as 80 to a non-plastic silt, in a random sequence. 


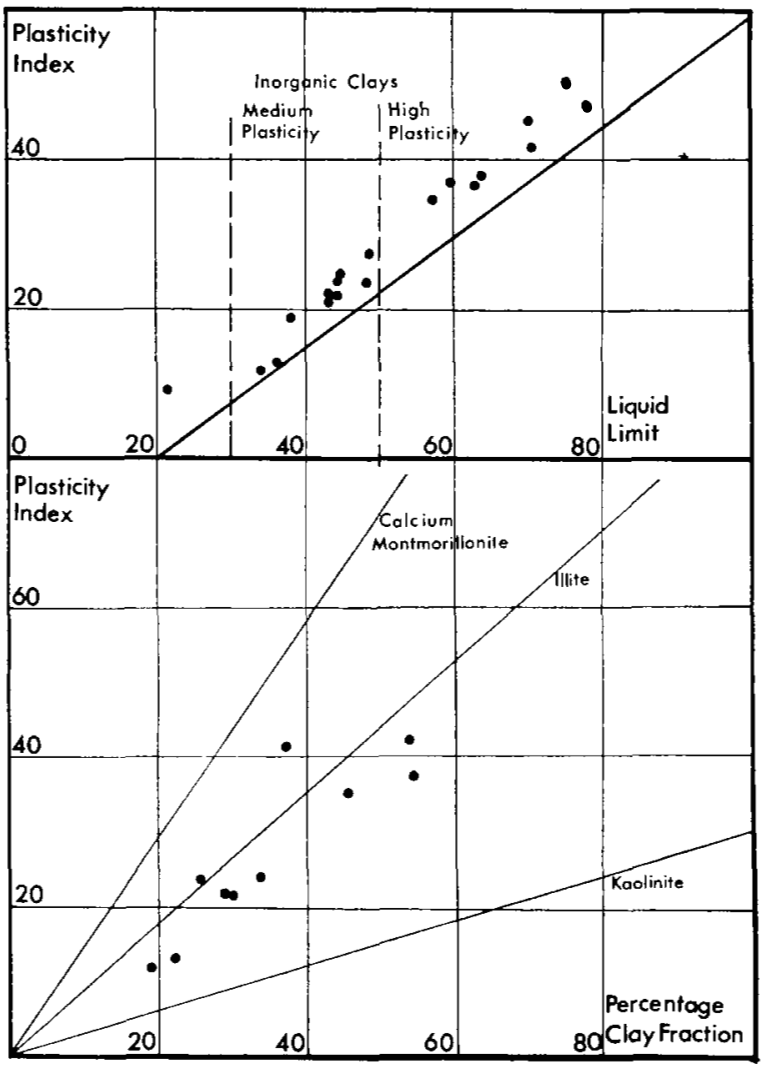

Fig. 10. Classification of alluvium in Severn Estuary (Avonmouth) area, showing wide variations in index properties and predominance of Illite.

57. A vertical profile of undrained shear strength test results, taken to depth, resembles Fig. 11. To the right hand side the moisture contents are enveloped round the average of about $41 \%$. To the left, the strength/depth relation starts with the common 'measles effect' within the zone of desiccation, but below about $6.00 \mathrm{~m}$ the field and laboratory vane tests tended to group themselves along a $C_{u} / p$ line of 0.15 to $0 \cdot 30$.

58. The presence of silt laminations was evident from the trial embankment results. As a consequence, on the job itself, the Engineers were able to rely on field rates of settlement 5 to 8 times faster than predictions from a small laboratory test model.

59. The time/settlement curves shown in Fig. 12 are derived from 11 of the rod gauge points installed at the start of actual construction. At these points two time rates of settlement were obtainable. The first was provided by the initial embankment loading, and the second by the surcharge or final loading. For comparison the vertical scale of settlement is plotted as a percentage of the total. Where the loading period was significant a correction is also made for this; otherwise the actual field time-scale remains unchanged. The initial loadings relate to a ground pressure 


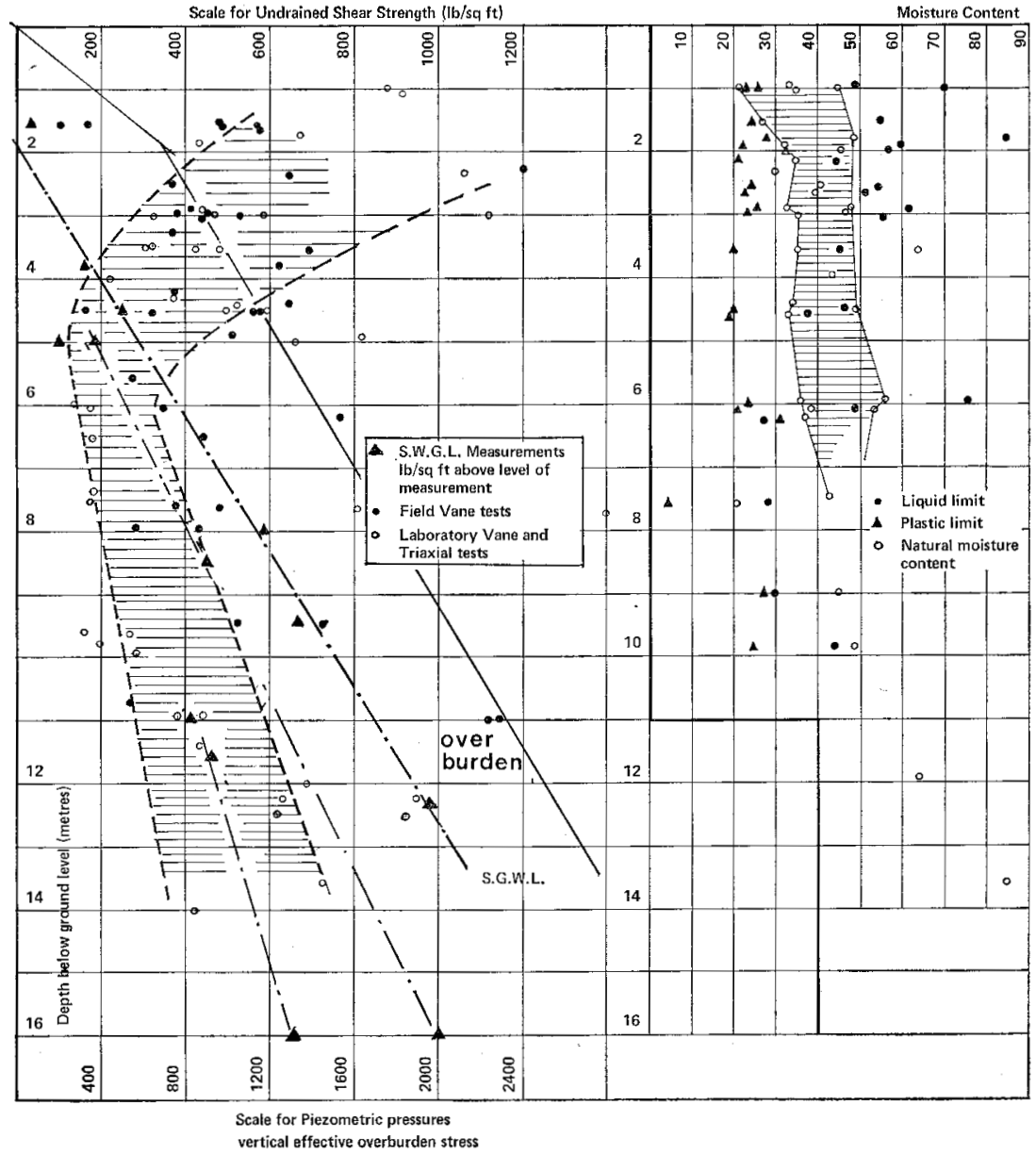

Fig. 11 (above). Vertical profile of undrained strength vs depth, showing $C_{\mathrm{u}} / p$ variation of $0.15-0.30$

Fig. 12 (top right). Envelope of time/settlement curves from 11 rod gauge settlement recording points (time rates of settlement show negligible sensitivity to depth of alluvium)

Fig. 13 (bottom right). Measured vertical strains in grey-blue silty clays vs embankment pressure (log scale) 

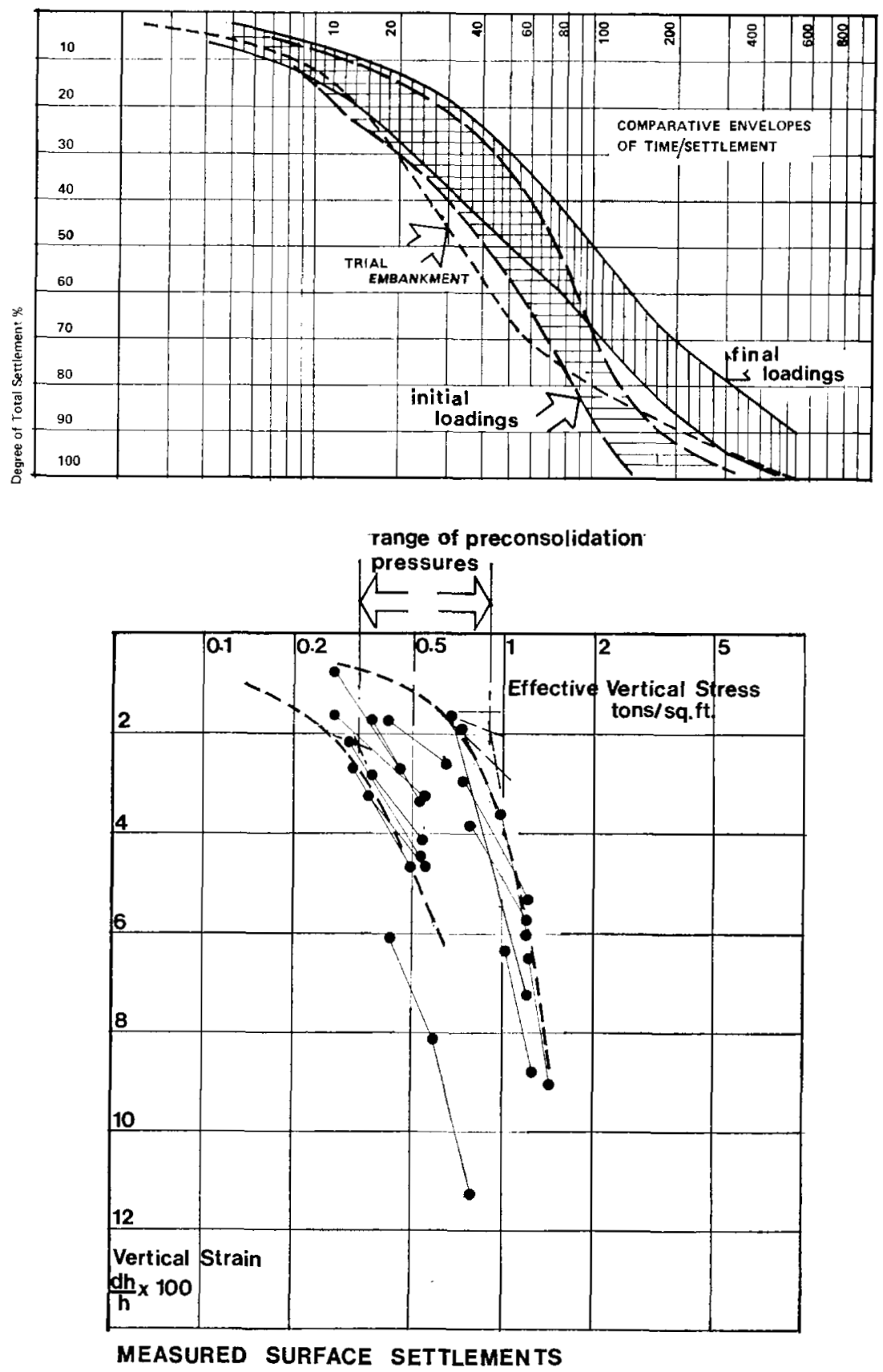
of the order of $0.50 \mathrm{ton} / \mathrm{sq}$. $\mathrm{ft}$ or less; the second loading was for pressures up to 2.0 ton/sq. ft. In Fig. 12 the two groupings are enveloped and plotted together.

60. The total thickness of alluvium, consisting of the clays, peats, silts and sands, varied between 20 and $40 \mathrm{ft}$ at the points where these measurements were taken. Yet a quite close correspondence in time rate of settlement was observed within each grouping. There would appear to be a marginal sensitivity only to the vertical drain path. Generally the lighter or initial loadings settled out more quickly than the heavier loadings. By comparison the rate of settlement under the trial embankment was the most rapid.

61. The foregoing would seem to suggest that it was not the vertical, but the horizontal drainage which was the influencing factor in the time rate settlement. Comparison with the trial embankment must reconcile a different drainage condition in this respect. At the rod gauge points the water path would be confined to one horizontal axis; that is, from the centreline outward. The trial bank on the other hand was roughly square, so flow could occur on two horizontal axes, analogous to a radial drain condition. If the assumption of horizontal drainage is correct, then a more rapid settlement would be expected from the trial bank.

62. Secondly, I wish to refer to the preconsolidation aspects of the material. In this area it classifies into four or five zones, namely the desiccated crust, a grey-blue clay, silty clays, peat, silts and sand. In general at least $60 \%$ of the material at any one point falls within a classification of the soft grey-blue clay and/or silty clay. Therefore, in order to obtain the comparative settlement plot shown in Fig. 13, the thicknesses of the other zones at each rod gauge point were adjusted to an equivalent thickness of this main deposit. This was done by multiplying the actual thickness of each of the remainder in the ratio of its compressibility to that of the clay. Normalizing the results in this manner makes the single assumption that the model laboratory test samples provided values of compressibility which could be taken as comparative.

63. This enables the actual measured settlement to be plotted as a percentage of the 'equivalent' thickness of clay in Fig. 13. Inevitably there is a fairly wide scatter in the final result which can only be anticipated where the variables cannot be completely defined. The significance of the result however focuses on the quite sharp bend in the curve at surface loadings around 0.50 ton/sq. $\mathrm{ft}$ which indicates some measure of preconsolidation.

64. There is a variety of explanations for preconsolidation. A history of desiccation throughout the period of deposition could be a contributing cause in this case. Preconsolidation is calculable from carefully performed laboratory tests, where the test curve is reconstructed according to Schmertmann's procedure. Seven such tests completed by this procedure are shown in Fig. 14. It is noteworthy that the values of compression index thus obtained, when measured against liquid limit, show a fairly consistent plot on the usual classification basis.

65. The over-consolidation ratio, that is, the preconsolidation pressure divided by its existing overburden pressure, varied between unity (no consolidation) and 3 . Four results grouped within the range 1.2 to 1.6. Dr Bjerrum, when referring to the Norwegian clays, put forward a value of 1.6.

66. I should like to conclude with a tribute to the engineers on the job itself, $\mathrm{Mr}$ Michael Lewis and Mr Phillip Holland, who undertook the tedious job of preparing and maintaining 26 sets of records which are reported here. The time involved in this part of the operation is far greater than the time taken afterwards to read them, or maybe misread them. Sometimes the best intended programmes for record measurements falter because of their time-consuming nature, which highlights the value of the work done here during the course of construction.

Mr F. S. Nundy, John Laing Construction Ltd

As a contractor currently engaged on the construction of one of the contracts forming the western extension of the M5 over basically similar type of ground I have read the 


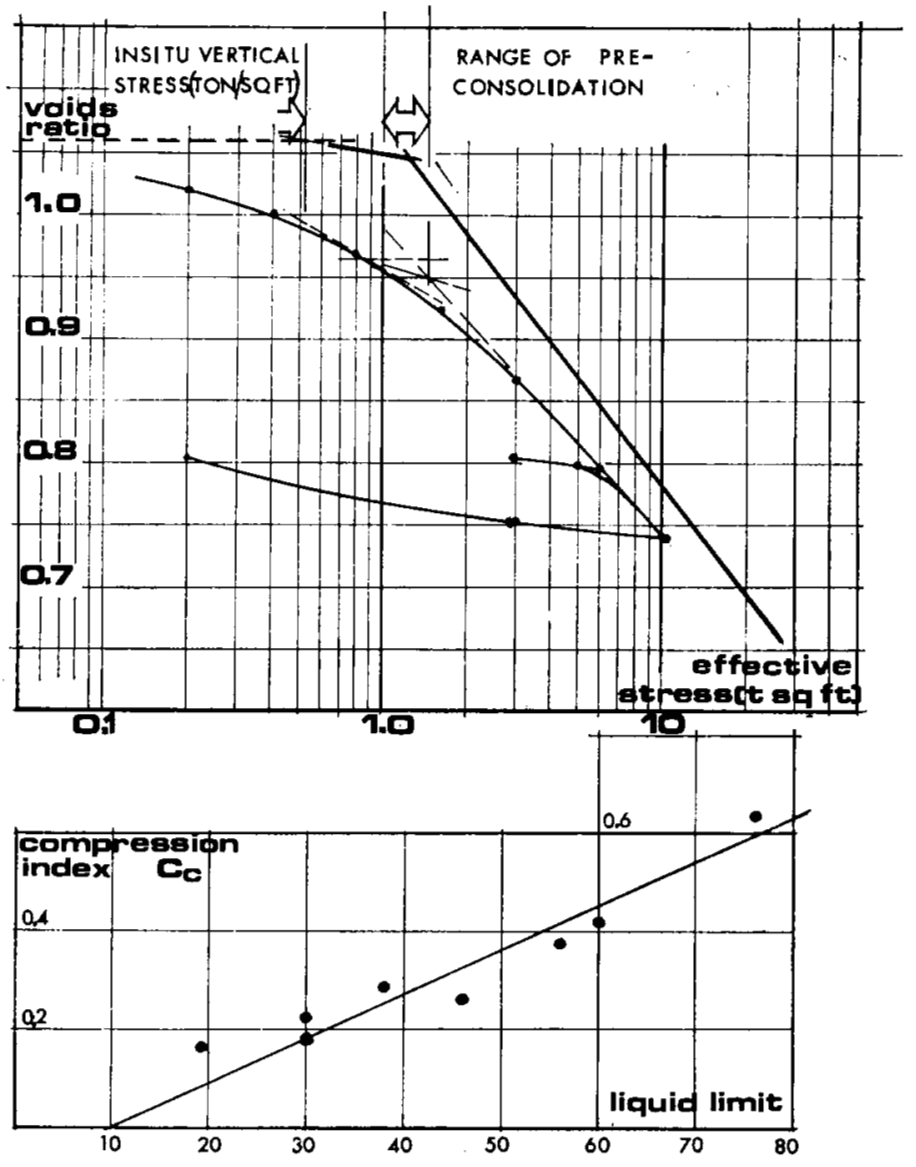

Fig. 14. (a) Typical laboratory oedometer test showing calculation of preconsolidation pressure (after Casagrande and Schmertman ; $(b)$ compression index vs liquid limit for eight tests (value of $C_{\mathrm{c}}$ measured from reconstructed curve)

Paper with great interest, not only from the aspect of learning what the other fellow had to do but also as it is of great interest to know the design philosophy and the background behind what one is currently engaged upon.

68. Civil engineering design tends to follow an evolutionary process and this is very true of this type of approach to the problem of constructing motorways over alluvial plains. The Paper develops the steps in the construction of the first stage of the motorway where the soft underlying material extended for a depth of approximately $40 \mathrm{ft}$. This same basic design approach has now been further developed to permit the motorway to be carried out over areas where the soft material is over $90 \mathrm{ft}$ thick. It could be said that if one is able to do it for a depth of $40 \mathrm{ft}$, what does a little more matter, but knowing the consistency of the 'toothpaste' in question I would say that it matters a very great deal. 
69. From this point of view, the accurate interpolation of the answers provided by the instrumentation of the test embankment has permitted the embankment described in the Paper to be constructed. Current contracts have similarly been designed from information obtained from this original embankment. It is to be hoped that just as much useful data will be obtained for the future from the current tests on our contract as has been from those described in the Paper.

70. From the contractor's point of view it is a nightmare to protect the instrumentation during the time that the major bulk earthworks are under construction, and I only hope that we have been able to leave enough for some valuable information to be obtained.

71. For the contractor this type of contract poses an extremely difficult organization problem. Initially one is required to set up a large and complex organization to provide the material for the embankment and surcharge in the shortest possible time. This requires a momentum to be built up on the contract which can only be obtained by the development of a high degree of esprit de corps among the people engaged on the operation.

72. On the completion of the first stage the momentum falls off as the major part of the works are sterilized when they lie dormant for up to a year. Nothing destroys esprit de corps on a contract quicker than inactivity. But immediately the year is over the whole road, including the majority of the structures, has to be built in the shortest possible time, calling for an even higher momentum than before to be achieved. Nevertheless it is undoubtedly a most economical approach to this type of problem, provided that the time is available for the long settlement period involved, and the problems set to the contractor in respect of his contract organization must be looked upon as one of the unfortunate necessary outworkings.

73. It is noted that in the Paper only an estimated site bulk density for the p.f.a. was quoted. It would be of interest if the Author would please state the lab dry density, optimum moisture content and average delivered moisture content for the p.f.a. used within the Contract. It is also noted that the Author states that a method specification was arrived at for the compaction of the p.f.a. In view of the continuing problems that surround the compaction of this material, would the Author please state the details of the specification used on the Contract?

\section{Mr A. D. M. Penman, Building Research Station}

I would like to make three points. The work described shows close cooperation between the Government's Road Research Laboratory and the Consultants, Freeman Fox and Partners. One had the impression that the geotechnical content could have been improved by closer cooperation in writing the Paper.

75. Settlements are caused not only by consolidation of the underlying soft soil, but also by its displacement sideways. In connexion with oil tanks at Teesmouth I found discrepancy between settlements calculated from the results of triaxial $K_{0}$ tests and those which actually occurred under the centre of a tank. This was caused by displacement of soft foundation soil. The sideways displacements of the foundation soil was measured at four positions around another tank with inclinometer tubes. This work has been described elsewhere.

76. The rate of settlement of the oil tanks was much greater than that calculated from laboratory tests, largely due to the extensive system of drainage afforded by sand partings, etc., within the body of the soil. The actual time of settlement was about 30 times faster than that predicted, to a value which may be compared with the Author's 8 and 90 . The influence of geological features on the drainage of clay deposits has been discussed by Professor Rowe ${ }^{8}$ and others, and one technique used nowadays to make allowance for this effect is to measure the in situ permeability of the soil by constant head tests on piezometers, then to use this value in conjunction with compressibility measured by oedometer tests to obtain a realistic value for the coefficient of consolidation. 
77. Engineers should really be designing for acceptable movements, not just so as to provide an adequate factor of safety against complete collapse. The Author has probably been doing this in fact: he has used a factor of safety of 1.7 as his lower limit because he feared that a lower value would produce unacceptable movements. But what movements are acceptable? During design the Author used values of 0.16 and $0.08 \mathrm{ft}(\$ 17)$ as permissible values for residual settlements: how were these figures arrived at?

78. An indication of horizontal strains has been given by a movement of 13 in. at one culvert joint and this suggests that horizontal plate gauges of the type described by Penman et al. ${ }^{9}$ would have given valuable information about both horizontal movements and settlements and avoided the use of rod settlement gauges, which are a nuisance to any contractor and often lose their value completely after accidental damage.

\section{Mr F. H. Hughes, Cementation Ground Engineering Ltd}

There is a great need for data on trial and main embankments founded on alluvium. I am particularly interested in sand drains, and in vibroflotation. Two years were available for the trial embankment, and two years for the motorway embankment construction itself. Normally in work on, for example, oil tanks, where time is not so readily available, the loading, surcharge, and an appreciable amount of consolidation settlement have to take place in something like six months. This usually means that some foim of ground treatment is needed. In many cases, however, valuable months are wasted before the loading gets under way. It is pleasing to learn about a wisely planned embankment construction.

80. I was interested to see the surcharge cost. I wondered what the $£ 95000$ covered. It is sometimes difficult to plan to have surcharge available, and to spend money moving it in and out. It is usually easier on motorway projects where there are side roads or minor embankments which can be fitted into the programme to take the surcharge after use. With oil tanks, a water load is often used to surcharge the ground. Where it is necessary to use an earth surcharge in order to get rid of most of the settlement before the tank is built, the cost of this surcharge can be quite significant unless it is possible to re-use the material a number of times.

81. Dr Hawkins has shown that the type of material in this alluvial plain is very heterogeneous, so that if one starts on an exploration programme involving the taking of very large samples, the cost could be excessive. Initially the inspection of borehole specimens, especially if near-continuous sampling can be undertaken, is valuable. On this site it appears that horizontal drainage controls the consolidation. In order to assess the problem, I personally would elect to have an initial inspection of many specimens, followed by a limited programme of undisturbed sampling. If it were possible to build a trial embankment on a selected area I would certainly opt for this rather than a programme of large-scale sampling.

82. There is however a problem with the trial embankment. If the drainage is mainly horizontal, and consolidation is controlled by horizontal drainage, then the time for consolidation is probably controlled by the width of the load. With sand drains the time for consolidation for radial drainage depends upon the square of the effective spacing. In the same way the time for consolidation from horizontal drainage under an embankment must depend upon the square of the horizontal drainage path, which in turn depends upon the embankment width. Thus, if the main embankment is much wider than the trial load, it is likely that the time for a given consolidation will be longer. The small trial may well give a too favourable result.

83. I was interested to note that the permeability of the blanket was as low as $10^{-4} \mathrm{~cm} / \mathrm{s}$. The ratio of the permeability of the blanket to that of the soil is $10^{4}$; this is just about the limit given by Gibson and Shepherd ${ }^{10}$ for an efficient drainage layer. Was the blanket permeability that after field compaction? There is a problem with 
some soils in that they tend to break down on placement to become less permeable than indicated by the laboratory tests.

84. I was very pleased to see that the vegetation was not cleared off. There seems to be a reluctance amongst road engineers in this matter, but it certainly is wise for operation over otherwise soft ground. In my opinion a thin layer of top soil contributes very little to the settlement problem, and, indeed, it might in itself be a very useful drainage path. I have had operating problems where the soft ground is at surface level. It is important to have a running blanket placed even before the drainage blanket proper, to allow the machinery access to the site.

85. I was interested that the trial embankment was incorporated into the new fill. Did this cause a problem with regard to differential settlement?

86. On the matter of differential settlement I should like to pose a question to structural engineers. Do bridges in alluvial areas always have to be placed on relatively stiff foundations? There is a case for the foundation design of the embankment and bridge as a unit and not separately.

87. Many piezometers were placed under the embankment. I should like to know their casualty rate. How many were in action towards the end of the trial and the two-year construction period? Also, what was the correlation between piezometers and settlement gauges? In our vibroflotation work we have found that some of the piezometer measurements are inclined to be unreliable. This is not always a function of installation. Sometimes they act as if they have flap valves attached to them! They are inclined to show a rise but refuse to show a corresponding fall in pore pressure. We have obtained better information on the loading from settlement gauges.

\section{Mr W. F. T. Austin, Freeman Fox \& Partners}

All engineers, when they have seen a job with which they have been associated in its finished state, ask themselves if they would do it the same way again. We have done that in the case of this length of road at Avonmouth, and generally speaking I think the answer I would give is that we think that this technique has been successful. In spite of settlements varying between 1 and $2 \mathrm{ft}$ during construction the ride, after over a year of use, is still smooth.

89. It is about ten years since a very preliminary soil survey, even more preliminary than the one referred to in the Paper, was made and in that soil survey we were advised that the maximum height of embankment that could be built on this ground was $7 \mathrm{ft}$. However, we thought that if these embankments could be built slowly and carefully using p.f.a. in some cases the ground would strengthen up under the weight and it might be possible to improve considerably on that figure. When repeating work of this nature we would make a little more allowance for the sideways plastic flow of material under the bank, to which previous speakers have referred.

90. Having said we would do the same thing again, I would add a word of caution. Reference has been made by Mr Nundy to the next section of the work, where the soft ground is much worse and deeper. We did another trial embankment to prove that even on worse ground it could be done. That failed and it made us more careful when we built a third, and this time successful, trial embankment.

91. There have been some references by Mr Penman to the safety factor of 1.7 , and he rightly questions this. With great care during construction it is possible to go to the point where there are signs of incipient failure and to get the bank up to the required height this sometimes has to be done. With subsequent dissipation of excess pore-water pressure an adequate safety factor for the permanent work is obtained.

92. I was surprised by the success of the hydro-seeding on the bank. I had never looked upon fly ash as particularly good garden soil, but even after two years the growth of grass was still very good. 
Dr P. R. Vaughan, Imperial College

I would like to sound another note of warning concerning the use of deformation measurements to control construction. In soils which do not show brittle failure characteristics, construction will be limited by prefailure deformation. ${ }^{11}$ In soils which show brittle failure characteristics, failure may be concentrated in local zones and overall deformations just prior to failure may be small and quite acceptable. Moreover, failure may be sudden and followed by large post-failure displacements. Therefore, where such soils are involved, an adequate factor of safety against shear failure must be maintained during construction, irrespective of shear deformation.

94. It is difficult, on the basis of current knowledge, to predict whether brittle failure will occur and what strains will precede it for a particular foundation. Thus it would be very useful if, where trial embankments are used and where failure during construction may be critical, part of the trial construction is taken close to failure. The type of failure and the magnitude of the deformations preceding it can then be demonstrated.

95. It is most desirable that the risk of sudden brittle failure at small displacement of the embankment should be considered where measurement of deformation forms part of the means of construction control.

Mr B. G. Combridge, P. \& T. Department, Construction Branch, Greater London Council

The settlement diagram in Fig. 6 seems to indicate a fairly regular rate of settlement over the 550 days or so. May I ask Mr Dallard whether there is any evidence that this settlement was at all seasonal? In a $1 \frac{1}{2}$ years period, within a contract of $2 \frac{3}{4}$ years, starting in March, it is not clear whether this embraced one or two winters. In any case, is there any evidence that this would have made any difference to the rate of settlement or the total time during which settlement may have been achieved?

\section{Messrs A. McGown and J. S. Younger, Strathclyde University}

The construction of high quality roadworks over soft compressible soils presents a difficult engineering task and one which often exposes the differences between predicted soil behaviour, based on standard testing techniques, and the observed soil behaviour. The case history reported by Mr Dallard is an example of this.

98. The pore-water pressures beneath the trial embankment and final embankment dissipated more quickly than was predicted. This, as the Author states, is in line with a number of other case records of similar construction problems. The likely fault, we suggest, lies not so much in basic theory as in the methods adopted for the measurement of the soil parameters and the method in which the theory was applied to the problem.

99. The Author states that a conventional site investigation was carried out, and thus it can be assumed that $\mathrm{U} 4$ samples were taken and thereafter 3 in. dia. standard laboratory oedometer tests were undertaken. The parameters so measured would be dependent on the rate of vertical dissipation of pore water in the test specimen. The degree of disturbance to the macro- and micro-structure, or complete absence of macro-structure in the test specimens would greatly influence the value of the parameter so measured. As no indication of sampling disturbance and no description of rootlets or silt seams is given for the soil, it is possible that the laboratory determined soil parameters were at variance with those relating to in situ behaviour.

100. The wide scatter of shear strength results suggests either highly variable soil conditions or moderately sensitive soils which have been disturbed to varying degrees by the progress of the site investigation. In addition, no mention is made of the water level in the boreholes during drilling operations, nor of the effect on shear strength of rapidly executed undrained tests with fixed ends; both could contribute to the wide scatter of results obtained, particularly for the type of soil encountered. 
101. As no lateral drainage properties were measured it is likely that the assumed drainage pattern from beneath the trial embankment would not have taken proper account of lateral drainage; in fact, it is not clear what drainage boundaries were assumed. Dependent upon the macro-structure of the soil and the configuration of the loaded area, the lateral drainage could have been a very significant feature, influencing the rate of consolidation. At the initial design stages, unless delayed consolidation effects had been discerned, it would have been possible to have taken account of simultaneous lateral and vertical drainage under the embankment, employing numerical techniques and an extension of the simple one-dimensional consolidation expression. ${ }^{12}$

102. It is suggested that much of the observed discrepancy between field and predicted behaviour of soft soils beneath embankment results from the errors inherent in conventional techniques for sampling, testing and analysis. For instance, the standard oedometer can be sufficiently accurate for measurements of coefficient of compressibility $\left(m_{\mathrm{v}}\right)$, but is normally totally inadequate for the assessment of the coefficient of consolidation, $\left(C_{\mathrm{v}}\right)$. Use of larger diameter sampling and testing and more sophisticated analysis based on the conventional theories gives a more realistic prediction of behaviour. Where in situ permeability measurements can be made under appropriate conditions, predictions can be further refined.

\section{Mr Dallard}

I thank Mr Murray for his contribution to the discussion; but most of all I am grateful for his and the Road Research Laboratory's contribution to the trial embankment experiment. The further research being carried out by the Laboratory together with work already completed will lead, I hope, to the formation of a data bank on which engineers can draw.

104. Dr Hawkins's short talk was interesting and of practical value to the engineer. It is apparent that geologists like Dr Hawkins and engineers should get together at an early stage when placing of embankment on weak alluvium is being considered. He said that the use of solid lines between boreholes could be misleading; he is correct if the engineer making the calculations forgets that the lines represent generalizations and expects an accuracy of result that is unobtainable.

105. Mr Cook has gone to a great deal of trouble to look into records and to plot curves of relationships; and I thank him for what he has done. His proposition that the bi-directional horizontal drainage condition under the square trial embankment was more favourable to drainage, and therefore to settlement, than the uni-directional condition under the rectangular motorway embankment seems sensible. If he is correct then a trial embankment should be built to represent closely the ultimate road embankment, its length being several times its width. I should like to add to $\mathrm{Mr}$ Cook's tribute to Messrs Lewis and Holland my own appreciation of their work.

106. Mr Nundy's comments on a contractor's problems in building embankments on soft alluvium were both interesting and useful. In reply to his questions on p.f.a., the average delivered moisture content was $35.5 \%$ which was about the same as that which met the Proctor test requirement for maximum dry density. The average bulk density in the embankment was $92 \mathrm{lb} / \mathrm{cu}$. ft which was close to the value of 90 assumed in design. The method specification for compaction of p.f.a. called for use of a vibrating roller with a deadweight of $30 \mathrm{cwt}$. Compaction was allowed to be carried out only when the moisture content was not greater than $36 \%$ or less than $25 \%$. These facts relate, of course, to the particular p.f.a. used successfully on one particular job and should not be assumed to apply to other sources of the material which varies according to source.

107. Mr Penman remarked on the apparent lack of geotechnical content in the Paper. If he is correct, this was certainly not due to lack of co-operation between the Consultants and the Road Research Laboratory. The purpose of the Paper was solely to demonstrate how an engineer makes use of a scientist's data in order to build 
a road. The Road Research Laboratory's Report ${ }^{6}$ covers geotechnical aspects in greater detail. In regard to Mr Penman's remarks on the factor of safety against collapse and acceptable movements, the Engineer must check for both independently and satisfy himself on both counts. There must not be sufficient settlement, particularly differential settlement, to cause accidents on a motorway where vehicles travel at $70 \mathrm{mile} / \mathrm{h}$. The values of 0.08 and $0 \cdot 16 \mathrm{ft}$ of residual settlement were chosen in order to determine the amount of surcharge required so that a judgement could be made. In the event it was decided for practical constructional reasons, bearing in mind the test results, to apply $3 \mathrm{ft}$ of surcharge throughout. The resulting rideability of the road seems to have proved that the amount was correct.

108. I am grateful to Mr Hughes for his remarks. The figure of $£ 95000$ covered everything in connexion with placing and removal of surcharge, including placing some of it in the main embankment on the approach to Avonmouth Bridge. The permeability of the blanket was measured after field compaction. There has been no problem of differential settlement where the new fill joined the trial embankment; the fact that the road levels fall away to the west from the trial embankment level was of assistance in this respect.

109. Manometers in groups A, B, C and D were damaged and successfully repaired and all groups were in use throughout the construction period. However, the greatest casualty rate was that of rod settlement gauges. The pore pressure-time relationships plotted for all groups showed the trend expected and a sensible correlation with settlement readings. Could it not be that the nature of the vibroflotation work that $\mathrm{Mr}$ Hughes referred to, as compared with the construction operation at Avonmouth, gives rise to disturbance of the subsoil which affects the piezometers?

110. I thank Mr Austin for his contribution. I should also like to record that when the scheme was in its infancy he correctly predicted what the ultimate solution would be.

111. Dr Vaughan's warning about deformation measurements controlling construction is wise indeed. But to take a trial embankment that will be incorporated later in the main works close to, or up to, failure, presents an Engineer who is responsible to a Client (who usually controls public funds) with a difficult decision. Perhaps a data bank, such as I referred to in my reply to Mr Murray, based on pure scientific experiment as opposed to real works, will allow an Engineer to make judgements which do not depend on testing to a point of near failure.

112. Mr Combridge's question on seasonal effect is covered in the Report referred to earlier ${ }^{6}$ (para 5.6). The embankment appears to provide a blanket to the subsoil which remains at more or less constant temperature, according to depth, throughout the seasons.

113. Messrs McGown and Younger have reinforced my view that conventional techniques for sampling, testing and analysis are unreliable. Obtaining an "undisturbed' sample which really is undisturbed and testing in such a way as to account for all drainage paths is most likely to be achieved through a full-scale trial embankment experiment. Perhaps centrifuge testing of a large sample will provide the correct answers. We shall see.

\section{References}

6. Murray R. T. Embankments constructed on soft foundations. RRL Report $L R$ 419. Road Research Laboratory, Crowthorne, 1971.

7. Penman A. D. M. and Watson G. H. Foundations of storage tanks on reclaimed land at Teesmouth. Proc. Instn Civ. Engrs, 1967, 37, (May) 19-42.

8. Rowe P. W. Influence of geological features of clay deposits on the design and performance of sand drains. Proc. Instn Civ. Engrs, 1968, Suppl. vol. 1-72. 
DISCUSSION

9. Penman A. D. M. et al. Observed and predicted deformations in a large embankment dam during construction. Proc. Instn Civ. Engrs, 1971, 49, (May) $1-21$.

10. Gibson R. E. and Shepherd G. C. The efficiency of horizontal layers for accelerating consolidation of clay embankments. Géotechnique (Lond.), 1968, 18 (Sept.) 327-335.

11. Vaughan P. R. Undrained failure of clay embankments. Proc. Roscoe Memorial Symposium. G. T. Foulis \& Co Ltd, Henley on Thames, 1972, p. 683.

12. Carillo N. Simple two and three dimensional cases in the theory of consolidation of soils. J. Math. Phys., 1942. 